\title{
16 ANOS DEPOIS DA LEI 10.639/03: OUVINDO MENINOS E MENINAS (NEGROS E NÃO NEGROS) DE UMA ESCOLA DO EXTREMO SUL CATARINENSE
}

\author{
16 YEARS AFTER OF THE LAW 10.639 / 03: LISTENING BOYS AND GIRLS \\ FROM AN EXTREME SOUTH CATHARIAN SCHOOL
}

\author{
Amanda dos Santos Vieira ${ }^{1}$ \\ Lucy Cristina Ostetto ${ }^{2}$
}

\begin{abstract}
RESUMO: Com o objetivo de compreender como a Lei 10.639/03 - alterada pela Lei 11.645/08 - que torna obrigatório o ensino de História e Cultura Afro-Brasileira, está sendo trabalhada em uma escola pública, ouvimos crianças concluintes do ensino fundamental anos iniciais no ano de 2018. Para tanto foram realizadas entrevistas semiestruturadas com seis alunos, negros e não negros, de uma escola estadual do extremo sul catarinense com o propósito de dialogar com as crianças e analisar seus conhecimentos desenvolvidos durante os primeiros anos do ensino fundamental tendo como ponto de análise a Lei 10.639/03, transformada em 11.645/08. Para isso, dialogamos com Lima (2010), Wieviorka (1946), Bolsanello (1996), Brasil (1890), Guimarães (1999), Waiselfisz (2014), Bento (2002), Santos (2005), Trevisan (2013), Sales (2015), Trapp (2011), Brasil (1996), Brasil (2001), Brasil (2003), Santos (2001), Brasil (2013), Cavalleiro (2001). Assim, foram abordadas questões relacionadas ao racismo, período da escravidão e pós-escravidão, motivo da vinda dos africanos para o Brasil, como se estruturou a sociedade no Brasil e qual a importância das populações negras na formação da sociedade brasileira. Os alunos entrevistados demonstraram através das suas falas a não aplicação da Lei 10.639/03 dentro desta instituição de ensino, revelando uma desinformação sobre temas básicos como escravidão, tinham incertezas sobre quais as contribuições dos negros para a sociedade e o que é racismo, confundindo-o com bullying.
\end{abstract}

PALAVRAS-CHAVE: Educação. Lei 10.639/03. Escola. Reflexões de alunos. Racismo.

ABSTRACT: In order to understand Law 10.639/03 — amended by Law 11.645/08-, which makes compulsory the teaching of Afro-Brazillian History and Culture, on a public school. We heard children who were graduating the first years of elementary school on 2018. Therefore Semi-structured interviews were performed with six students, black and non-black,

\footnotetext{
${ }^{1}$ Graduada em Pedagogia. Mestranda em Educação, Universidade do Extremo Sul Catarinense, membro do Grupo de Pesquisa em Direitos Humanos, Relações Étnicos-Raciais e Feminismo[s]. E-mail:

amanda.s.vieira@hotmail.com

${ }^{2}$ Professora Doutoranda em História pela Universidade Federal de Santa Catarina; Professora pela Universidade do Extremo Sul Catarinense - UNESC, coordenadora do Grupo de Pesquisa em Direitos Humanos, Relações Étnicos-Raciais e Feminismo[s]. E-mail: lco@unesc.net
}

Saberes Pedagógicos, Criciúma, v. 4, n², maio/agosto 2020.- Curso de Pedagogia- UNESC 


\section{SABERES PEDAGÓGICOS}

Revista do Curso de Graduaçāo de Pedagogia - Unesc

ISSN $2526-4559$

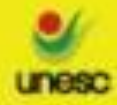

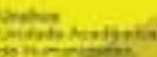

in a public school on the far south end of the SC state with the purpouse of dialoguing with the children and analyze their developed knowledge during the first years of basic education, having the focus of analysis Law 10.639/03, turned into Law 11.645/08. For this we discussed Lima (2010), Wievorka (1946), Bolsanello(1996), Brasil(1890), Gumarães (1999), Waieselfisz (2014), Bento (2002), Santos (2005), Trevisan (2013), Sales (2015), Tapp (2011), Brasil (1996), Brasil (2001), Brasil (2003), Santos (2001), Brasil (2013), Cavalleiro(2001). Thus, questions related to racism, slavery history and post-slavery, reasons for african immigration to Brazil, how society was structured on Brazil and what's the importance of black populations on the formation of the brazilian society. The interviewed studens showed through their speech the non aplicaiton of Law 10.639/03 inside this educational institution, revealing a misinformation of basic themes such as slavery, they had uncertainties about black people contribution to society as well as racism, mistaking it with bullying.

KEYWORDS: Education. Law 10.639/03. School. Student Reflections. Racism.

\section{INTRODUÇÃO}

A Lei 10.639/03, redigida durante o governo Lula, “altera a Lei no 9.394, de 20 de dezembro de 1996, que estabelece as diretrizes e bases da educação nacional, para incluir no currículo oficial da Rede de Ensino a obrigatoriedade da temática 'História e Cultura AfroBrasileira', e dá outras providências" (BRASIL, 2003). Sendo alterada pela Lei 11.645/08, que vem incluir a cultura Indígena também (BRASIL, 2008). Esta Lei determina que a escola, pública e privada, deve incluir o estudo das lutas dos negros e africanos, bem como sua participação na formação da sociedade e sua história, para que assim possa se tirar do silenciamento sua extrema importância para a narrativa do Brasil.

Esta pesquisa teve início dentro do Grupo de Pesquisa em Direitos Humanos, Relações Etnicorraciais e Feminismo[s], que se propõe a desenvolver leituras e debates sobre as questões de raça, de gênero, decolonialidade, relações raciais dentro do país, racismo, entre outros temas vinculados a direitos humanos. Por meio destas leituras e debates foi possível uma maior identificação sobre racismo em seus vários âmbitos, como científico, institucional e questões de embranquecimento, entre outros. Sendo assim, a Lei 10.639/03 é um documento essencial como ponto de partida para entender tais entrelaces.

Haja vista que a Lei 10.639/03 torna obrigatório o ensino de "História e Cultura Afro-Brasileira", é questionável se esta é aplicada dentro das salas de aula. Para tanto, esta pesquisa buscou responder se a Lei estava sendo aplicada partindo das falas das crianças. $\mathrm{O}$ Saberes Pedagógicos, Criciúma, v. 4, n², maio/agosto 2020.- Curso de Pedagogia- UNESC 
objetivo geral, portanto, é compreender se há a aplicação da Lei 10.639/03, partindo da reflexão das crianças. E como objetivos específicos, perceber os percursos da lei, compreender como o racismo foi estruturado no Brasil, analisar como o racismo é tratado dentro da escola - tendo em vista que já ocorreram casos de racismo dentro da instituição -, e por fim reafirmar a importância do cumprimento da Lei.

Para se alcançar estes objetivos, a metodologia utilizada foi de pesquisa qualitativa, com estudo de campo e pesquisa bibliográfica. Na coleta de dados, as entrevistas semiestruturadas foram aplicadas com os alunos concluintes do ensino fundamental anos iniciais, dentro de uma instituição estadual de ensino do extremo sul catarinense. A escola é localizada em um ambiente predominantemente de descendentes de italianos e com diferenças de classes extremas. Nesse sentido, viu-se a necessidade de analisar como os alunos, tanto negros quanto brancos, independentemente de sua classe, têm acesso à história do país e da formação da sociedade através das lentes da Lei 10.639/03.

No primeiro momento trata-se sobre como as teorias racistas foram trazidas ao Brasil e como até hoje se mantêm sendo uma estrutura de poder. Dialogamos com Lima (2010), Wieviorka (1946), Bolsanello (1996), Brasil (1890), Guimarães (1999), Waiselfisz (2014), Bento (2002). Em um segundo momento, o enfoque se volta a como a luta do Movimento Negro foi essencial para a aprovação da Lei 10.639/03, e os autores para referência foram Santos (2005), Trevisan (2013), Sales (2015), Trapp (2011), Brasil (1996), Brasil (2001).

Por fim, a Lei 10.639/03 e como esta deve se estabelecer dentro da escola, sendo os autores Brasil (2003), Santos (2001), Brasil (2013), Cavalleiro (2001). Na terceira parte há a análise de dados das entrevistas semiestruturadas realizadas com os alunos, na qual o referencial teórico é utilizado como base para analisar a aplicabilidade da lei. Enfim, a conclusão de todo o percurso da pesquisa e as referências bibliográficas utilizadas para o desenvolvimento do estudo.

\section{RETRATOS DE UM BRASIL RACISTA}

Para se falar sobre a Lei 10.639/03 e as relações raciais no Brasil, é necessário Saberes Pedagógicos, Criciúma, v. 4, n², maio/agosto 2020.- Curso de Pedagogia- UNESC 
antes tratar do tema que foi um dos embasamentos para que tenha sido protocolada: o racismo. Segundo IBGE (2014), a população que se declara negra e parda representa 53,6\% da população brasileira e mesmo assim ainda existem dois sintomas que percorrem todos os lugares: a suposta superioridade branca, sendo enfatizada pelo racismo científico, e o mito da democracia racial, que faz acreditar que todos somos brasileiros e humanos, logo qualquer preconceito é uma falácia. Segundo Lima (2010, p. 88),

\begin{abstract}
Consequentemente, pode-se dizer que o termo 'raça' em seu aspecto biológico, político e cultural atuou na sociedade como mecanismo hierarquizante das diferenças entre as pessoas. E hierarquizar significou perceber nos grupos sociais brancos seres superiores em relação aos grupos negros e mestiços que compunham até então parcela significativa da população brasileira.
\end{abstract}

Vale então ressaltar que o termo raça e todas as suas ramificações, a serem tratadas a seguir, não chegaram ao Brasil sem nenhum propósito, veio, como cita Lima (2010), para hierarquizar a sociedade que aqui se estabelecia. E as teorias que aqui se propagaram contam com o mesmo princípio: explicar através da ciência como a superioridade branca é algo válido.

Segundo Wieviorka (1946), o Racismo Científico trabalha com a visão da existência de "raças". Assim as características físico-biológicas estão totalmente ligadas às questões intelectuais/psicológicas, sendo elas coletivas, fazendo-se presentes em cada indivíduo. Sendo assim, cria-se a visão de que só por ser negro, por exemplo, a pessoa já está determinada a seguir um padrão que também se faz presente em todos os outros negros. De acordo com Schwarcz (1993, p. 23-24 apud LIMA, 2010), o Racismo Científico chegou ao Brasil ainda durante a escravidão, juntamente com a chegada da família real, em 1808. Como se caminhava para a abolição da escravatura, D. João VI implantou no Brasil instituições de ensino superior e de pesquisas com o objetivo de replicar o ideal já estabelecido no exterior de dominação colonial. Sendo assim, manteria a ideia de inferioridade da população negra que estava a ponto de ter sua liberdade conquistada. Condizente com estas visões, Lima (2010) diz que as teorias raciais vieram a incutir no imaginário social a visão de que haveria/há diferença entre as habilidades e capacidades, correlacionando com aspectos psicológicos, cognitivos e morais, utilizando-se assim dessas supostas distinções entre raças para sustentar a visão de 
raças superiores a outras.

Enquanto o Racismo Científico estabelece um padrão para um coletivo, o Darwinismo Social tem um teor mais individualista. Segundo Bolsanello (1996), o Darwinismo Social veio estabelecer que a desigualdade é algo natural, sendo assim os seres humanos já nascem com algumas aptidões, podendo ser elas superiores ou inferiores. Dessa forma, alguns já nascem para o sucesso/riqueza e outros para o fracasso/pobreza. De acordo com Lima (2010), o Darwinismo Social, assim como outras teorias racistas, não chegou ao Brasil por acaso. Estas tinham como função fazer do país uma nação moderna e civilizada, seguindo os padrões europeus. Para alcançar este objetivo, se estabelece a visão de inferioridade racial dos negros e mestiços no país. Lima (2010) reforça que hierarquizar os sujeitos levando como ponto de partida a questão de raça foi uma estratégia utilizada pelos países europeus para que estes aumentassem seus domínios e determinassem a colonização em países/territórios que fossem considerados inferiores, porém vistos como ótimos para a economia e seus negócios.

Chega ao Brasil o conceito de Eugenia, e, conforme Lima (2010), os defensores desta teoria estavam voltados para a questão de aperfeiçoamento da raça humana. Mantinham a ideia de que se devia manter uma raça pura para que não ocorresse degeneração da humanidade, negando assim a mestiçagem. Dessa forma, os defensores desta ideologia acreditavam que o "branco europeu" era o reflexo do que existia de raça civilizada. Acreditavam que a Europa só se encontrava no status de civilização devido a sua população ser formada, em sua maioria, por pessoas brancas.

Com o fortalecimento das campanhas abolicionistas, se caminhava para o fim da escravidão. Em 13 de maio de 1888 se assinou a Lei Áurea (BRASIL, 1888), que decreta: "Art. 1': É declarada extincta (sic) desde a data desta lei a escravidão no Brazil (sic). Art. $2^{\circ}$ : Revogam-se as disposições em contrário". De acordo com Lima (2010), não houve preocupações por parte do Estado, dos senhores ou de instituições para dar auxílio aos negros libertos viverem em sociedade e em relação aos novos formatos de trabalho. Dessa forma se constata que a abolição não teve como enfoque a melhoria de vida dos negros, mas sim satisfazer interesses do próprio país/Estado.

O pós-abolição não se estruturou de forma que desse apoio aos negros e a Saberes Pedagógicos, Criciúma, v. 4, n², maio/agosto 2020.- Curso de Pedagogia- UNESC 
possibilidade de uma vida digna. Conforme Lima (2010), as teorias racistas deixaram rastros que marcaram os negros livres e libertos, já que além de inferiores eram vistos como "sem preparo", ignorantes, vadios e preguiçosos. Essas visões dificultaram a inserção social e ao trabalho, sendo que nenhum apoio ou trabalho foi desenvolvido para a incorporação destes à sociedade. E isso só se alastrou com o Decreto nº 847, de 11 de outubro de 1890 (BRASIL, 1890) que instituía:

\section{DOS VADIOS E CAPOEIRAS}

Art. 399. Deixar de exercitar profissão, officio (sic), ou qualquer mister em que ganhe a vida, não possuindo meios de subsistência (sic) e domicilio certo em que habite; prover a subsistência (sic) por meio de ocupação (sic) prohibida (sic) por lei, ou manifestamente ofensiva (sic) da moral e dos bons costumes:

Pena - de prisão cellular (sic) por quinze a trinta dias. [...]

Art. 402. Fazer nas ruas e praças públicas exercicios (sic) de agilidade e destreza corporal conhecidos pela denominação capoeiragem (sic); andar em correrias, com armas ou instrumentos capazes de produzir uma lesão corporal, provocando tumultos ou desordens, ameaçando pessoa certa ou incerta, ou incutindo temor de algum mal:

Pena - de prisão cellular (sic) por dous (sic) a seis mezes. (sic)

Paragrapho unico. (sic) E' considerado circumstancia (sic) aggravante (sic) pertencer o capoeira a alguma banda ou malta.

Aos chefes, ou cabeças, se imporá a pena em dobro.

Dessa forma, além de não se colaborar para a introdução do negro na sociedade, criou-se ainda mais barreiras. De acordo com Lima (2010, p. 105), "passaram a viver à margem da sociedade, habitando os piores lugares e em condições degradantes e por conseqüência ( $(\mathrm{ic})$, desempenhavam funções de baixo prestígio social”.

A Democracia Racial surge como a visão que o Brasil viveu/vive em clima de harmonia entre as raças. Esta visão se estabeleceu principalmente dentro do livro Casa-grande e Senzala de Gilberto Freyre (2000 apud LIMA, 2010). Neste o autor traz a visão de que a mestiçagem racial estava ligada a uma relação harmoniosa entre as raças que constituíam a sociedade brasileira, afirmando juntamente que o período de escravidão foi algo harmonioso e que seria um facilitador para a convivência entre os grupos.

Quando tratamos de Democracia Racial a visão base é que somos todos humanos, sendo assim todos são iguais e que discutir a questão de raça é que se apresenta como racista.

Saberes Pedagógicos, Criciúma, v. 4, n², maio/agosto 2020.- Curso de Pedagogia- UNESC 


\section{SABERES PEDAGÓGICOS}

Revista do Curso de Graduaçāo de Pedagogia - Unesc

ISSN 2526-4559

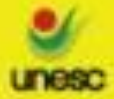

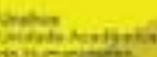

No domínio da “democracia racial”, culpado (reprovável) é aquele que tenta apresentar o discurso racial, racista ou não, na forma do discurso sério, público e formal, tematizando as relações raciais: reconhecer a idéia ( $\mathrm{sic}$ ) de raça e promover qualquer ação anti-racista baseada nessa idéia (sic) é interpretado como racismo (GUIMARÃES, 1999 apud SALES JUNIOR, 2006, p. 251).

Dentro desta perspectiva, todos têm o mesmo ponto de partida e têm assim o mesmo direito. Ignora-se assim, por exemplo, os anos de escravidão, assim como o fato que após seu término os negros não tiveram nenhum apoio real, basicamente foram ignorados/escorraçados ou forçados a trabalhar por misérias. De acordo com Lima (2010), para Freyre “[...] a identidade brasileira seria una e indivisa, não havendo espaço para preconceitos de raça e cor, e tampouco discriminação racial". Criou-se assim a visão de que no Brasil todos viviam em perfeita harmonia e que a escravidão não veio a interferir em nada nas relações sociais. Porém, a escravidão trabalhou para o aumento da diferença entre a realidade de pessoas negras e não negras, problemas que vieram a se firmar e aumentar com o passar dos anos.

O Racismo Institucional, por fim, está relacionado com a questão de desigualdade presente em diversos lugares e como essas atitudes/ações vêm a reforçar o racismo. De acordo com Souza (2011), Racismo Institucional está relacionado as políticas institucionais que vêm a produzir/reproduzir a desigualdade utilizando a questão de raça como ponto de partida para tal.

De acordo com Rex (1987, p. 185, apud SOUZA, 2011, p. 3), "o conceito de Racismo Institucional refere-se a políticas institucionais que, mesmo sem o suporte da teoria racista de intenção, produzem consequências desiguais para os membros das diferentes categorias raciais".

Há ainda a perspectiva do branqueamento. Segundo Bento (2002), o branqueamento tende a ser considerado um problema especificamente do negro, que ao não aceitar sua realidade tende a optar por uma identificação com o branco e até mesmo se miscigenar para reduzir suas características físicas. Assim ao levantar esta questão o branco pouco se faz presente, sendo que é levado como modelo universal e aquele que serve de "inspiração" aos negros dentro deste processo de embranquecimento. Entretanto, ao se estudar o processo de branqueamento entende-se que isso foi inventado e sustentado por uma elite 
branca. Esta visão vem a se fazer presente em frases como "é um negro de primeira linha", que vem a demonstrar que para ser bom naquilo que está realizando este deve ter algum traço de branco ou se distanciar da realidade negra. Como por exemplo quando Barroso (2015, apud MARIZ, 2017) chamou o ex-presidente do STF, Joaquim Barbosa, de negro de primeira linha, reforçando assim determinada visão.

Por fim, conforme Lima (2010), é essencial ter consciência de que os negros não são vistos como inferiores ou sofrem discriminação racial somente quando são pobres, o que vem a se suceder seria que a discriminação vem se tornar menos visível no decorrer da ascensão social dos negros.

O branqueamento durante muito tempo foi visto como uma estratégia de transformar o Brasil em uma nação unicamente branca-europeia. Alguns cientistas na época enxergavam na mestiçagem uma forma de embranquecer a população. Como o branco era visto como um elemento superior, ao se cruzar o "branco" com o "negro" nasceria um mestiço mais embranquecido. Seria uma forma natural de embranquecer as relações raciais no país (LIMA, 2010). Vale ressaltar que "o projeto de branqueamento do país foi implementado através do investimento no imigracionismo, antes mesmo do fim da escravidão." (LIMA, 2010, p. 110).

É importante compreender que, segundo Felipe e Teruya (2018), antigamente a ideia de raça superior/inferior auxiliou a fortificar a escravidão, já que negros eram inferiores. E hoje esta ideia ainda continua a estruturar as relações raciais no Brasil, não sem a resistência das populações negras.

\section{O MOVIMENTO NEGRO E OS PERCURSOS DA LEI 10.639/03}

O movimento negro no Brasil vem de longa data, foi e é permeado por vários atravessamentos, embates e lutas. Um dos primeiros passos rumo a uma educação antirracista foi dado quando, segundo Santos (2005), os movimentos negros, ao observarem que os sistemas de ensino no Brasil reproduziam a discriminação contra si e contra seus descendentes, reivindicaram seus direitos na declaração do I Congresso do Negro Brasileiro, que ocorreu em 1950. Dentro do congresso foi recomendado, conforme Nascimento (1968, p.

Saberes Pedagógicos, Criciúma, v. 4, n², maio/agosto 2020.- Curso de Pedagogia- UNESC 
293 apud SANTOS, 2005, p. 23), “o estímulo ao estudo das reminiscências africanas no país bem como dos meios de remoção das dificuldades dos brasileiros de cor e a formação de Institutos de Pesquisas, públicos e particulares, com esse objetivo".

Outro passo importante foi dado durante o governo Fernando Henrique Cardoso, também conhecido como FHC. Segundo Trevisan (2013), foi apenas em 1995 que o expresidente FHC admitiu que o Brasil ainda era um país racista e que havia desigualdade racial. Nesse mesmo ano, de acordo com Santos (2005), foi realizada a Marcha Zumbi dos Palmares Contra o Racismo, Pela Cidadania e a Vida, e seus líderes negros e negras foram ao encontro do presidente, novamente manifestaram as questões de discriminação racial e apontaram o racismo contra os negros no país e o descaso com a educação. De acordo com Trapp (2011), após a marcha o governo, para suprir as demandas do Movimento Negro, implantou o Grupo de Trabalho para a Valorização da População Negra (GTI), dentro da área da Secretaria Nacional dos Direitos Humanos (SNDH), criando um tensionamento para que as políticas públicas afirmativas e as demandas exigidas pelo Movimento Negro entrassem para a agenda nacional.

Durante a gestão do próprio FHC foi fundado o Programa Nacional de Direitos Humanos (BRASIL, 1996b). Este tinha como um dos seus objetivos apresentar a história dos negros nos livros didáticos, demonstrando a importância deles para a construção da sociedade. O programa pode ser visto como uma forma de tentar quebrar o silenciamento sobre a história do país no que tange à presença da população negra.

A escola sempre foi o principal enfoque destas leis, que tinham como objetivo modificar a visão racista que se faz presente no cotidiano de todos. A Lei de Diretrizes e Bases da Educação (BRASIL, 1996a) veio reforçar que a história do Brasil deveria dar enfoque também aos diferentes povos que estavam envolvidos na formação do país, sendo estes os indígenas, africanos e europeus. Assim, as instituições de ensino tinham agora, como obrigação, incluir estas temáticas dentro do conteúdo "História do Brasil".

A Conferência Mundial Contra o Racismo, a Discriminação Racial, a Xenofobia e a Intolerância Correlata, ficando conhecida como Conferência de Durban, ocorrida no ano de 2001 em Durban - África do Sul, pode ser considerada outro passo que contribuiu para a criação de novas políticas públicas relacionadas às questões raciais. Conforme Trapp (2011),

Saberes Pedagógicos, Criciúma, v. 4, n², maio/agosto 2020.- Curso de Pedagogia- UNESC 
foi no país de Nelson Mandela, que sofreu durantes anos com o apartheid, que se reuniram governos nacionais, a ONU, ONGs e movimentos sociais de todo mundo para tratar de questões como racismo, xenofobia, intolerância na contemporaneidade.

Thomaz e Nascimento (2003) afirmam que durante a conferência o governo brasileiro apontava os avanços dentro do país quando a questão era a superação da injustiça histórica, referindo-se à escravidão. Por outro lado, os movimentos enfatizavam que havia ainda muito a se percorrer, dando ênfase que o país não teria políticas públicas tratando da questão racial. A conferência veio a tratar de temas como discriminação de gênero, de imigrantes, questões de segregação por castas, antissemitismo, entre outros. Segundo a Declaração e Programa de Ação da Conferência Mundial Contra o Racismo, a Discriminação Racial, a Xenofobia e a Intolerância Correlata (BRASIL, 2001):

Enfatizamos os vínculos entre o direito à educação e a luta contra o racismo, discriminação racial, xenofobia e intolerância correlata e o papel essencial da educação, incluindo a educação em direitos humanos, e a educação que reconheça e que respeite a diversidade cultural, especialmente entre as crianças e os jovens na prevenção e na erradicação de todas as formas de intolerância e discriminação.

Cabe assim aos países aplicarem tais pontos dentro de suas agendas políticas. O governo brasileiro, em 2003, criou a Secretaria Especial de Políticas de Promoção da Igualdade Racial (SEPPIR). Segundo um documento da própria SEPPIR (2009), esta foi criada como uma resposta para as deliberações da Conferência de Durban - da qual o Brasil fez parte com a maior delegação e ainda fez a relatoria geral -, sendo assim uma forma de reconhecer todas as lutas do movimento negro e outros movimentos contra a discriminação racial. No ano de 2008, a SEPPIR ganhou o status de ministério dentro do governo do expresidente Luís Inácio "Lula” da Silva.

Após anos de luta do Movimento Negro, em 2003 foi sancionado a Lei 10.639/03, que prevê:

Art. 26-A. Nos estabelecimentos de ensino fundamental e médio, oficiais e particulares, torna-se obrigatório o ensino sobre História e Cultura Afro-Brasileira. $\S 1$ o $\mathrm{O}$ conteúdo programático a que se refere o caput deste artigo incluirá o estudo da História da África e dos Africanos, a luta dos negros no Brasil, a cultura negra brasileira e o negro na formação da sociedade nacional, resgatando a contribuição do povo negro nas áreas social, econômica e política pertinentes à História do Brasil.

Saberes Pedagógicos, Criciúma, v. 4, n², maio/agosto 2020.- Curso de Pedagogia- UNESC 
$\S 2$ ㅇ Os conteúdos referentes à História e Cultura Afro-Brasileira serão ministrados no âmbito de todo o currículo escolar, em especial nas áreas de Educação Artística e de Literatura e História Brasileiras.

Art. 79-B. O calendário escolar incluirá o dia 20 de novembro como "Dia Nacional da Consciência Negra". (BRASIL, 2003).

Tais obrigatoriedades devem estar presentes tanto nas escolas públicas quanto privadas e ser aplicadas durante todo o currículo escolar, caminhando assim para fora do ciclo apenas de contar histórias que dão enfoque à hegemonia europeia, assim como a questão de trabalhar a história de negros/africanos apenas em datas específicas, como 20 de novembro/13 de maio, ou ligado à história do continente africano.

De acordo com Santos (2005), ao analisar a Lei em nível distrital, em Brasília, bem como em alguns outros municípios, esta estabelecia também a revisão dos currículos e a qualificação dos professores. Sendo assim, a Lei, nestes lugares, se manteve atenta ao fato que é necessário não apenas sancionar a Lei, é preciso também preparar os professores para aplicá-la.

A Lei 10.639/03 é vista como uma ação afirmativa. Segundo o Ministério da Educação (MEC) (BRASIL, 20??), "Entende-se por ações afirmativas o conjunto de medidas especiais voltadas a grupos discriminados e vitimados pela exclusão social ocorridos no passado ou no presente". De acordo com o MEC (BRASIL, 20??), as ações afirmativas têm como seu objetivo "eliminar as desigualdades e segregações", para que não haja grupos superiores e inferiores na sociedade, sem o predomínio de raças, gênero, classe, etc.

Vale ressaltar que a Lei 10.639/03 vem a auxiliar em uma educação antirracista, e conforme Cavalleiro (2001, p. 149):

No cotidiano escolar, a educação anti-racista visa à erradicação do preconceito, das discriminações e de tratamentos diferenciados. Nela, esteriótipos e idéias (sic) preconcebidas, estejam onde estiverem (meios de comunicação, material didático e de apoio, corpo discente, docente, etc.), precisam ser duramente criticados e banidos. É um caminho que conduz à valorização da igualdade nas relações. E, para isso, o olhar crítico é a ferramenta mestra.

Condizente com isso, segundo Santos (2001, p. 106) ao tratar de discriminação social deve-se compreender que não é um problema das crianças negras, podendo ser visto como uma oportunidade de crianças brancas e negras "se conhecerem, discutirem e Saberes Pedagógicos, Criciúma, v. 4, n², maio/agosto 2020.- Curso de Pedagogia- UNESC 
instaurarem novas formas de relação, que tenham impacto em suas vidas e na sociedade como um todo".

Em 2008, conforme Goularte e Melo (2013), o Brasil tem como sua marca a diversidade social e vários povos formam a identidade nacional, principalmente os índios que habitavam o território mesmo antes dos colonizadores, viu-se a necessidade de reconhecer e respeitar a cultura indígena. E para tal foi sancionada a Lei 11.645, que segundo Brasil (2008)

Altera a Lei $\mathrm{n}$ 으 9.394, de 20 de dezembro de 1996, modificada pela Lei $\mathrm{n} \underline{\mathrm{O}}$ 10.639, de 9 de janeiro de 2003, que estabelece as diretrizes e bases da educação nacional, para incluir no currículo oficial da rede de ensino a obrigatoriedade da temática "História e Cultura Afro-Brasileira e Indígena".

Sendo assim, altera a Lei 10.639/03, incluindo dentro de seus objetivos como Lei o ensino da Cultura Indígena também. No dia 17 de junho de 2004 foi assinada a Resolução CNE/CP n 01 de 2004, que institui as Diretrizes Curriculares Nacionais para a Educação das Relações Étnico-Raciais e para o Ensino de História e Cultura Afro-Brasileira e Africana, que segundo o MEC (BRASIL, 2013b) “[...] são o instrumento legal que orienta para o cumprimento da Lei $n^{\circ} 10.639 / 03$ [...]”. Esta veio nortear como iria ocorrer a aplicação da Lei 10.639/03 dentro de todos os âmbitos escolares e qual seria a função de cada órgão governamental.

De acordo com o Plano Nacional de Implementação das Diretrizes Curriculares Nacionais para a Educação das Relações Étnico-Raciais e para o Ensino de História e Cultura Afro-Brasileira e Africana (BRASIL, 2013a), cabe às instituições de ensino privadas e públicas que o tema História e Cultura Afro-Brasileira deve ser trabalhado, interdisciplinarmente, dentro de todo o contexto escolar, principalmente dentro da Literatura, Artes e Histórias Brasileiras. Tem como enfoque combater o racismo, discriminação e preconceito racial que vem a afetar os negros dentro da sociedade, e devendo se basear em pontos sociais, históricos e antropológicos da realidade brasileira. Condizente com isso, a Resolução CNE/CP nº 01/2004 (BRASIL, 2004) antevê que

Art. $3^{\circ}$ A Educação das Relações Étnico-Raciais e o estudo de História e Cultura AfroBrasileira, e História e Cultura Africana será desenvolvida por meio de conteúdos, competências, atitudes e valores, a serem estabelecidos pelas Instituições

Saberes Pedagógicos, Criciúma, v. 4, n², maio/agosto 2020.- Curso de Pedagogia- UNESC 


\section{SABERES PEDAGÓGICOS}

Revista do Curso de Graduaçāo de Pedagogia - Unesc

ISSN $2526-4559$

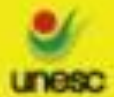

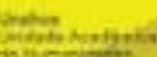

de ensino e seus professores, com o apoio e supervisão dos sistemas de ensino, entidades mantenedoras e coordenações pedagógicas, atendidas as indicações, recomendações e diretrizes explicitadas no Parecer CNE/CP 003/2004.

Sendo assim, a responsabilidade pela aplicação da Lei e das Diretrizes não cabe apenas ao professor, mas sim a toda a comunidade escolar. De acordo com isso, o Plano Nacional (BRASIL, 2013a, p. 38) é preciso "Reformular ou formular junto à comunidade escolar o projeto político-pedagógico adequando seu currículo ao ensino de história e cultura afro-brasileira e africana [...].”

Quanto ao ensino fundamental, o Plano Nacional (BRASIL, 2013a) cita que se deve realizar formações iniciais e continuadas aos professores pertencentes ao ensino fundamental para garantir a implementação dos conteúdos e desenvolver a educação para relações étnico-raciais. O documento prevê ainda ações como pesquisas, desenvolvimento de materiais didáticos, que promovam valores voltados para a educação em relações étnicoraciais. Condizente com isso, o Plano ainda vem a finalizar que se deve

\footnotetext{
Abordar a temática étnico-racial como conteúdo multidisciplinar e interdisciplinar durante todo o ano letivo, buscando construir projetos pedagógicos que valorizem os saberes comunitários e a oralidade, como instrumentos construtores de processos de aprendizagem. (BRASIL, 2013a, p. 51).
}

Sendo assim, a escola deve ter como presente em seu cotidiano as questões de raça e não apenas em momento pontuais. Todo este caminho veio a ser traçado para que vigorasse uma educação preocupada com a igualdade/equidade e principalmente cumprindo seu papel de antirracista. E assim atribuir valor à realidade e à trajetória das populações negras no Brasil, dando relevância a todos aqueles que auxiliaram a construção do país.

\section{INDO À ESCOLA E ESCUTANDO AS CRIANÇAS}

O objetivo desta pesquisa foi compreender se há a aplicação da Lei 10.639/03, partindo da reflexão das crianças em uma escola do extremo sul catarinense. Utilizou-se por uma abordagem de caráter qualitativo, que segundo Pinheiro (2010, p. 20) “caracteriza-se pela tentativa de uma compreensão detalhada dos significados e características situacionais 
apresentadas pelos entrevistados". Sendo a pretensão compreender os pontos da Lei por meio da fala dos entrevistados - que usaram como base o que aprenderam durante o ensino fundamental I -, focalizando assim na qualidade das informações passadas e não na quantidade. De acordo com Pinheiro (2010), a relação entre o mundo e o sujeito é indissociável e tal vínculo não pode ser medido em números.

Para coletar os dados, utilizou-se o formato de entrevista semiestruturada, com perguntas articuladas previamente para guiar o entrevistado. Segundo Boni e Quaresma (2005, p. 76), a entrevista semiestruturada é “[...] onde o informante tem a possibilidade de discorrer sobre o tema proposto. O pesquisador deve seguir um conjunto de questões previamente definidas, mas ele o faz em um contexto muito semelhante ao de uma conversa informal". Para assim compreender como os alunos visualizam a história do Brasil e de sua sociedade. Por meio dos relatos sobre as aulas e temas bases foi possível perceber a Lei fazendo-se ou não presente na sala de aula.

A escola escolhida está localizada no extremo sul catarinense, sendo esta estadual e na qual se desenvolve toda a educação básica. Os alunos que ali estudam, em sua maioria, têm descendência italiana e são considerados classe média. Por mais que haja uma variação dentro dos sujeitos que formam a sociedade desta cidade, contando com negros e não negros, o enfoque sempre se volta para a cultura italiana.

A pesquisa foi realizada com seis alunos, negros e não negros, concluintes do ensino fundamental anos iniciais no ano de 2018, para que assim fosse possível compreender se a Lei se fez presente dentro dos anos iniciais. Sendo assim, foram realizadas entrevistas semiestruturadas e individuais com cada criança, dentro do próprio ambiente escolar e em uma sala reservada. Algumas das crianças já eram conhecidas tendo em vista que fizeram parte da minha trajetória de formação. Para proteger a identidade dos alunos, foram utilizados nomes fictícios, sendo estes Benguela, sendo este uma criança com autismo, Cabinda, Mina, Nagô, Iorubá, Ijexá. Os nomes escolhidos se referem aos povos que foram trazidos para o Brasil durante o período da escravidão e contribuem até hoje na formação do país. Vale ressaltar que a pesquisa foi realizada com as crianças porque se faz necessário valorizar a fala destas enquanto refletem sua própria educação e os conhecimentos construídos durante sua passagem pelo ensino fundamental anos iniciais.

Saberes Pedagógicos, Criciúma, v. 4, n², maio/agosto 2020.- Curso de Pedagogia- UNESC 


\title{
SABERES PEDAGÓGICOS
}

Revista do Curso de Graduaçāo de Pedagogia - Unesc

ISSN $2526-4559$

\subsection{Dialogando com a reflexão das crianças}

Ao iniciar a pesquisa, foi solicitado que os alunos falassem suas idades e como se declaravam (brancos, negros ou pardos). Eles estão na faixa etária entre 11 e 12 anos, e dos seis alunos cinco se declararam brancos - Nagô se declarou negro. Ele também relatou que tem 12 anos, pois já seria a segunda vez que está no sexto ano do ensino fundamental. Condizente com isso, o projeto Todos Pela Educação (2016) vem a dizer que

\begin{abstract}
No Ensino Fundamental, embora no aspecto do acesso a diferença seja bem pequena, a desigualdade entre esses dois segmentos da população se acentua quando olhamos para aqueles que concluem a etapa na idade certa: $82,6 \%$ dos que se declaram brancos conseguem concluir o Fundamental até os 16 anos, enquanto entre pretos e pardos o percentual é de $66,4 \%$ e $67,8 \%$, respectivamente.
\end{abstract}

Enquanto os seus colegas irão concluir o Ensino Fundamental na idade dita como certa, Nagô já entra para a porcentagem daqueles que terão um atraso na conclusão desta fase. Quando questionados sobre o que conheciam sobre a formação da sociedade, levando em consideração os africanos, europeus e indígenas, Mina e Cabinda comentaram que não podia fazer bullying com os outros e que todos devem ser tratados da mesma forma, enquanto isso Benguela e Iorubá relataram não lembrarem nada.

Nagô respondeu que aprendeu um monte de coisa, porém não lembrava na hora. Por fim, Ijexá comentou que havia discutido este tema nas aulas de Ensino Religioso (apenas no $6^{\circ}$ ano). De acordo com Brasil (2013a), compete às escolas trazer as contribuições histórico-culturais das raízes africanas, europeus, povos indígenas e descendentes asiáticos para o seu contexto de atividades cotidianas e de seus estudos. O que não foi evidenciado pela maioria dos alunos.

Sobre a contribuição dos negros para a sociedade, Mina disse que eles ajudaram construindo materiais, minerando ouro. Benguela e Ijexá relataram não saber. Enquanto Nagô citou que "tudo, ajudaram a crescer" e Cabinda disse que "Alguns a mudar o mundo". Já Iorubá disse que pelo que se lembrava eles eram os escravos. Para Brasil (2013a, p. 40), "o ensino deve ir além da descrição dos fatos e procurar constituir nos alunos (as) a capacidade de reconhecer e valorizar a história, a cultura, a identidade e as contribuições dos

Saberes Pedagógicos, Criciúma, v. 4, n², maio/agosto 2020.- Curso de Pedagogia- UNESC 
afrodescendentes na construção, no desenvolvimento e na economia da nação brasileira”.

Quanto ao tema escravidão, Benguela, Nagô e Iorubá disseram não lembrar de nada. Mina disse que foi quando "os portugueses escravizaram muitos negros", Cabinda disse ser que os brancos antigamente procuravam negros e faziam de escravo. Já Ijexá explicou:

\begin{abstract}
Os brancos compravam os negros para serem escravizados, tipo mercado de escravos. Tinha gente que comprava criança para "criar" e para ser escravo futuramente, muitas vezes os brancos engravidavam as mulheres. Os escravos, pelo que eu lembro, eles lutavam capoeira. Só que eles falam para os brancos que era uma dança deles.
\end{abstract}

E sobre o pós-escravidão, Benguela, Nagô e Iorubá novamente não lembravam de nada. Mina respondeu que os negros foram viver a vida deles, enquanto Cabinda disse que eles ficaram livres da escravidão. Por fim, Ijexá relatou: "Eu sei que teve a Lei Áurea, que uma princesa/rainha lá assinou e eles foram libertos”.

Mina, Benguela e Ijexá disseram não se sentir diferentes de uma pessoa negra. Já Cabinda diz que não se sente diferente dos negros, “[...] mas, algumas pessoas sim. Porque elas acham que os negros são piores, que devem ser escravos. Porque não são da nossa cor". Iorubá reafirmou que são todos iguais. Nagô, por fim, diz que não se sente diferente de uma pessoa branca. Questionando este ponto de vista de igualdade, Lima (2010) vem a afirmar que “[...] 'somos todos brasileiros' apregoa uma falsa identidade nacional, incapaz de reconhecer os limites que as barreiras da cor impõem ao dia a dia de milhares de pessoas nesse país".

Ao serem questionadas sobre o que seria racismo, Mina e Cabinda disseram que seria quando se faz bullying com as pessoas, Mina ainda adicionou que o motivo do bullying seria por causa da cor da pele. Benguela disse que não sabia o que era racismo. Iorubá reforçou novamente que todos somos iguais e que seria quando uma pessoa branca faz preconceito com uma pessoa negra.

Ijexá afirmou que "racismo é aquilo de julgar pela cor da pele. Racismo é tipo julgar a pessoa pela cor da pele, se for negra chamar de apelido". Lima (2010) vem pontuar que o termo raça e as teorias raciais, todos os aspectos, vêm a atuar dentro da sociedade como uma estratégia de hierarquizar as pessoas através de suas diferenças, e isso significa os 


\section{SABERES PEDAGÓGICOS}

Revista do Curso de Graduaçāo de Pedagogia - Unesc

ISSN $2526-4559$

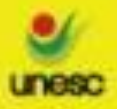

ationsones

grupos sociais brancos sendo superiores aos grupos de mestiços e negros. De acordo com Cavalleiro (2001, p. 149), uma educação antirracista "busca permanentemente uma reflexão sobre o racismo e seus derivados no cotidiano escolar".

Foram propostas duas situações de racismo para que os alunos dissessem como eles reagiriam, sendo elas quando uma pessoa faz uma piada racista e quando alguém chama o outro de macaco ou fala mal porque o cabelo é crespo. Mina disse que é uma oportunidade para "ensinar a pessoa que não pode fazer bullying e falar que cor de pele é a mesma coisa" e que ele falaria para a diretora. Benguela respondeu que não vê muito isso, porém recorreria à professora ou diretora. Cabinda afirmou que falaria que ao contrário, porque ela acha cabelo cacheado bonito e "defenderia seu amigo e falaria para a pessoa não falar mais, porque ele não gostaria que chamasse ele assim”. Iorubá disse que diria para pararem e ficaria triste. Já Ijexá respondeu que comunicaria alguém, porém relatou que "a gente tem medo."

Para completar o enfoque no tema racismo, foi apresentado um vídeo denominado Racimo Institucional (2016), que fez parte de uma campanha do Governo do Paraná contra o racismo. Neste, profissionais de Recursos Humanos são chamados para realizar um teste de imagem, no qual são apresentadas imagens de pessoas brancas realizando atividades cotidianas e depois imagens de pessoas negras na mesma situação, para assim analisar o que acreditavam que estas pessoas da imagem estariam fazendo.

O resultado foi que nas imagens de pessoas brancas estas estavam limpando sua casa, praticando corrida, seriam donos de empresas, já as pessoas negras eram empregadas domésticas, estavam fugindo e seriam seguranças. Após assistirem ao vídeo, Iorubá relatou que achou o vídeo falou muito sobre racismo, já Mina disse que não importa se a pessoa é branca ou negra, vai ser do mesmo jeito. Benguela se manteve em silêncio e não soube o que dizer, Cabinda afirmou que a imagem poderia não ser o que eles estavam pensando, que o homem correndo podia estar simplesmente correndo, relatou também que os negros também têm racismo contra os brancos. Nagô respondeu: "Os caras são idiotas. Branco correndo, falaram que tava atrasado. Negro correndo, acharam que tava fugindo”. Em concordância com esta visão, Ijexá comentou: 
causa da cor da pele, eles já acharam que era o contrário. Coisa ruim. Os brancos eles acharam que tava fazendo coisa boa, tipo a mulher que tava grafitando. Por exemplo, a mulher que tava limpando a pia, era dona de casa. Aí para o negro, a mulher que tava grafitando o muro tava chamando de pichadora e essas coisas. E tava limpando a pia também, chamaram de doméstica, essas coisas.

Conforme Cavalleiro (2001, p. 149), dentro do contexto escolar

a educação anti-racista visa à erradicação do preconceito, das discriminações e de tratamentos diferenciados. Nela, estereótipos e idéias ( ic ) preconcebidas, estejam onde estiverem (meios de comunicação, material didático e de apoio, corpo discente, docente, etc.), precisam ser duramente criticados e banidos. É um caminho que conduz à valorização da igualdade nas relações. E, para isso, o olhar crítico é a ferramenta mestra.

Nagô relatou já ter sofrido racismo, quando questionado em que lugar ocorreu disse que foi o motorista do ônibus da escola que o havia chamado de macaco. Relatou que ele ficou muito triste e que seu pai ligou para a escola, porém a instituição não tomou nenhuma providência. A escola já tem em seu histórico outro caso de racismo: no ano de 2015 um aluno entregou uma banana para a merendeira negra e disse que era pra ela, houve até um processo judicial no qual não se sabe qual foi o desfecho. Porém, nos dois casos a instituição se omitiu.

Conforme o Plano Nacional de Implementação das Diretrizes Curriculares Nacionais para a Educação das Relações Étnico-Raciais e para o Ensino de História e Cultura Afro-Brasileira e Africana (BRASIL, 2013, p. 39), cabe à escola "detectar e combater com medidas socioeducativas casos de racismo e preconceito e discriminação nas dependências escolares". O que não foi evidenciado.

\section{PARA NÃO CONCLUIR PORQUE O CAMINHO É LONGO}

\footnotetext{
A Lei visa educar a todos os brasileiros e brasileiras para que conheçam, respeitem e valorizem uma das raízes fundadoras de sua cultura e nacionalidade, a africana. $\mathrm{O}$ que precisa ser mudada não é a imagem dos negros, mas a imagem negativa que a sociedade criou e fomenta como se fosse própria deles (PETRONILHA, 2012, apud SOUZA, 2012).
} 


\section{SABERES PEDAGÓGICOS}

Revista do Curso de Graduaçāo de Pedagogia - Unesc

ISSN $2526-4559$

Dialogando também com Petronilha, relatora da Lei, buscamos por meio da escuta de crianças de uma escola pública estadual, compreender se e como a Lei 10.639/03 vem sendo trabalhada. Visto que é fundamental para mudar a imagem que o Brasil foi construindo sobre as populações negras e, neste sentido, perceber como o racismo institucional vem sendo reforçado. Principalmente, pela Lei se apresentar como uma ação afirmativa, instrumento dentro de um projeto de sociedade que minimize as desigualdades raciais e que dê visibilidade a população negra ao longo da história como formadora da sociedade, levando assim a necessidade de pedagogias outras com propósito antiracista. E não esquecendo que a obrigatoriedade da inclusão da história e da cultura africana e afro-brasileira tem força de Lei!

Vale ressaltar ainda que aplicar a Lei, não é apenas um conteúdo abordado! É uma questão de atitude, de posicionamento político. Por isso, tem peso de Lei e não se deve abordar apenas nas aulas de história, mas sim em todas as disciplinas, constar no Projeto Político Pedagógico, na formação continuada, nas reuniões pedagógicas, bem com dialogando com o Movimento Negro, o qual foi fundamental para a aprovação da Lei. Sobretudo, não se voltar somente para os alunos, mas envolver toda a comunidade escolar. Para que não se repita o que foi citado no caso de Nagô, no qual o motorista do ônibus escolar o chamou de macaco e a escola não tomou nenhuma atitude. O que demonstra um despreparo da instituição para lidar com situações como estas, não dando assistência e não trabalhando para combater o racismo dentro da própria escola e de sua comunidade, ou seja, sugere um total desconhecimento da Lei. O que se agrava após as falas de Mina, Benguela, Ijexá e o Nagô, que apontam para a direção da escola como referência para lidar com os casos de racismo. Suas falas nos suscitam questões como: Se faz presentes discussões relacionadas a Lei e seus objetivos dentro do Projeto Político Pedagógico da instituição? Houveram formações voltadas para os profissionais tanto da direção quanto aos pedagogos? Como se estruturam estes debates em torno da Lei 10.629/03 dentro do contexto desses profissionais, tendo em vista que estes pontos e discussões não chegam até os alunos?

Mina, Benguela, Ijexá, Iorubá, Nagô e Cabinda ainda desconhecem quais foram as contribuições das populações africanas e negras para a sociedade, bem como quem foram eles e como protagonizaram a história, até mesmo quando se trata do contexto da escravidão os alunos se mostram confusos ao definir o que foi esse período e quais foram suas marcas

Saberes Pedagógicos, Criciúma, v. 4, n², maio/agosto 2020.- Curso de Pedagogia- UNESC 


\section{SABERES PEDAGÓGICOS}

Revista do Curso de Graduaçāo de Pedagogia - Unesc

ISSN $2526-4559$

deixadas na população negra e na sociedade de modo geral. Demonstrando como essa história ainda se mantém silenciada. Quando se trata do tema racismo, os alunos confundem com bullying, e, neste sentido demonstraram não compreenderem como o racismo se estrutura de forma silenciosa dentro do cotidiano escolar. Ou seja, a Lei ainda não se faz presente como uma prática e postura dentro desta escola.

Para finalizar as entrevistas, e após assistirem o vídeo Racismo Institucional (2016), solicitou-se que os mesmos deixassem uma mensagem para uma sociedade na qual o racismo não se faça presente. Mina expressou que ele "Falaria que não podia ser racista com o outro, que seria bullying e você seria muito prejudicado." Associando assim o racismo a algo prejudicial, porém o confundindo com bullying. Benguela não sabia o que falar. Cabinda relatou que "[...] em vez dos brancos e dos negros brigarem, serem amigos. Porque não há nenhuma diferença entre nós.", trazendo novamente a visão de que todos são iguais, mostrando assim o desconhecimento de toda a estruturação do racismo dentro da sociedade. Já Nagô afirmou que "Racismo é crime", trazendo à tona a frase que aparece ao final do vídeo e demonstrando assim o sentimento que traz consigo pós evento já relatado de racismo. Iorubá propôs que "Pare de ser racista, porque as pessoas negras não merecem isso. Porque se você fosse a pessoa negra você não ia gostar disso.". Por fim, Ijexá disse que "Para deixar claro que todo mundo é igual. Não importa a cor, não importa a etnia, se é gordo, magro. Todo mundo é igual e todo mundo tem que se amar.", novamente a visão igualitária, porém trazendo o amor como solução, levando ao questionamento de como amar o que se desconhece ou que não se compreende suas dores? As crianças ainda não compreendem como uma sociedade racista se estrutura e impossibilita a questão de "todos iguais". E, neste sentido, a Lei 10.639/03 se cumprida, poderia desnaturalizar esta suposta igualdade, ou ainda explicitar historicamente o porquê estas diferenças existem. Não é sobre o negro, é sobre uma cultura e história de silenciamentos raciais.

E para que esta pesquisa auxilie ou até mesmo inicie um processo de reflexão sobre a sua aplicabilidade dentro da instituição, é necessário um retorno a escola para dialogar novamente com as crianças e levar até eles conceitos e visões ainda desconhecidas, para que através desde diálogo seja possível uma maior compreensão sobre temas que se relacionam com a Lei. Bem como, propor uma conversa com as professoras e direção, para voltar a

Saberes Pedagógicos, Criciúma, v. 4, n², maio/agosto 2020.- Curso de Pedagogia- UNESC 


\section{SABERES PEDAGÓGICOS}

Revista do Curso de Graduaçāo de Pedagogia - Unesc

ISSN 2526-4559

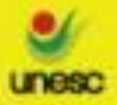

$+2$

discutir a importância do cumprimento da Lei para a vida das crianças e de todos que estão ligados a escola. Reafirmamos com Petronilha (2012 apud SOUZA, 2012) "Os sistemas de ensino e as escolas de diferentes níveis da educação [...] são espaços necessários e competentes para combater o racismo e discriminações [...]", desta forma é dentro da escola que a transformação se inicia.

\section{REFERÊNCIAS}

BENTO, Maria Aparecida Silva. BRANQUEAMENTO E BRANQUITUDE NO BRASIL. In: BENTO, Maria Aparecida Silva; CARONE, Iray. Psicologia social do racismo: estudos sobre branquitude e branqueamento no Brasil. Petrópolis: Vozes, 2002. p. 25-58. Disponível em: http://www.cehmob.org.br/wp-content/uploads/2014/08/Caderno-Racismo.pdf\#page=5. Acesso em: 21 maio 2019.

BOLSANELLO, M. A. Darwinismo social, eugenia e racismo científico: sua repercussão na sociedade e na educação brasileiras. Educar em Revista, Curitiba, v. 1, n.12, p. 153-165, 1996.

BONI, Valdete; QUARESMA, Sílvia Jurema. Aprendendo a entrevistar: como fazer entrevistas em Ciências Sociais. Revista Eletrônica dos Pós-graduandos em Sociologia Política da UFSC, Florianópolis, v. 2, n. 1, p.68-80, jan./jul. 2005.

BRASIL. Ações afirmativas. 20_. Disponível em: 〈http://etnicoracial.mec.gov.br/contato〉. Acesso em: 10 out. 2019.

BRASIL. Conferência Mundial Contra o Racismo, a Discriminação Racial, a Xenofobia e a Intolerância Correlata: Declaração e Plano de Ação. 2001. Disponível em:

<http://www.unfpa.org.br/Arquivos/declaracao_durban.pdf>. Acesso em: 10 out. 2019.

BRASIL. Decreto nº 847, de 11 de outubro de 1890. Promulga o Código Penal. Brasil, 11 out. 1890 .

BRASIL. Lei no 3353, de 13 de maio de 1888. Declara extinta a escravidão no Brasil. Lei Áurea. Brasil, 13 maio 1888.

BRASIL. Lei no 9394, de 20 de dezembro de 1996. Lei de Diretrizes de Bases: Estabelece as diretrizes e bases da educação nacional. BRASIL, 20 dez. 1996a. Disponível em: http://www.planalto.gov.br/ccivil_03/leis/19394.htm. Acesso em: 21 maio 2019.

BRASIL. Lei $\mathbf{n}^{\circ}$ 10639, de 09 de janeiro de 2003. BRASIL, 09 jan. 2003. Disponível em: http://www.planalto.gov.br/ccivil_03/leis/2003/110.639.htm. Acesso em: 21 maio 2019.

Saberes Pedagógicos, Criciúma, v. 4, n², maio/agosto 2020.- Curso de Pedagogia- UNESC 


\section{SABERES PEDAGÓGICOS}

Revista do Curso de Graduaçāo de Pedagogia - Unesc

ISSN 2526-4559

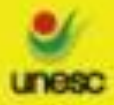

tations

BRASIL. Lei $\mathbf{n}^{\mathbf{0}} \mathbf{1 1 . 6 4 5}$, de 10 de março de 2008. Altera a Lei no 9.394, de 20 de dezembro de 1996, modificada pela Lei no 10.639, de 9 de janeiro de 2003 [...]. Brasil, 10 mar. 2008. Disponível em: http://www.planalto.gov.br/ccivil_03/_Ato2007-2010/2008/Lei/L11645.htm. Acesso em: 10 out. 2019.

BRASIL. Plano Nacional de Implementação das Diretrizes Curriculares Nacionais Para A Educação das Relações Étnico-raciais e Para O Ensino de História e Cultura Afrobrasileira e Africana. Brasília: Ministério da Educação, Secretaria de Educação Continuada, Alfabetização e Diversidade, 2013a.

BRASIL. Programa Nacional de Direitos Humanos. Brasília: Presidência da República, Secretaria de Comunicação Social, Ministério da Justiça, 1996b.

BRASIL. RESOLUÇÃO CNE/CP No 01 DE 2004 - 9 ANOS. 2013b. Disponível em: http://etnicoracial.mec.gov.br/noticias/106-resolucao-cne-cp-n-01-de-2004-9-anos. Acesso em: 10 out. 2019.

BRASIL. Resolução CNE/CP no 1, de 17 de junho de 2004. Institui Diretrizes Curriculares Nacionais para a Educação das Relações ÉtnicoRaciais e para o Ensino de História e Cultura Afro-Brasileira e Africana. Brasília, 17 jun. 2004.

CAVALLEIRO, Eliane. Educação anti-racista: compromisso indispensável para um mundo melhor. In: CAVALLEIRO, Eliane. Racismo e Anti-racismo na educação: Repensando nossa escola. São Paulo: Summus, 2001. p. 141-161.

EDUCAÇÃO, Todos Pela. A desigualdade entre negros e brancos também está na educação/. 2016. Disponível em: https://educacao.estadao.com.br/blogs/educacao-e-etc/adesigualdade-entre-negros-e-brancos-tambem-esta-na-educacao/. Acesso em: 10 out. 2019.

FELIPE, Delton Aparecido; TERUYA, Teresa Kazuko. Políticas públicas e o ensino da história e cultura afro-brasileira e africana na educação escolar. In: ALVES, Amanda Palomo; SILVA, Eronildo José da; ARAÚJO, Marivânia Conceição (Org.). Diálogos sobre diversidade, relações raciais e desigualdade no Brasil. Maringá: EDUEM, 2018. p. 229280.

GOULARTE, Raquel da Silva; MELO, Karoline Rodrigues de. A lei 11.645/08 e a sua abordagem nos livros didáticos do ensino fundamental. Entretextos, Londrina, v. 13, p.1-22, jul/dez., 2013.

IBGE - INSTITUTO BRASILEIRO DE GEOGRAFIA E ESTATÍSTICA. Pesquisa Nacional por Amostra de Domicílios: síntese de indicadores 2014. Rio de Janeiro: IBGE, 2015. Disponível em: https://biblioteca.ibge.gov.br/visualizacao/livros/liv94935.pdf/. Acesso em: 21 maio 2019.

Saberes Pedagógicos, Criciúma, v. 4, n², maio/agosto 2020.- Curso de Pedagogia- UNESC 


\section{SABERES PEDAGÓGICOS}

Revista do Curso de Graduaçāo de Pedagogia - Unesc

ISSN 2526-4559

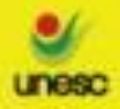

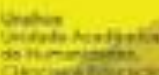

LIMA, Fernanda da Silva. A proteção integral de crianças e adolescentes negros: um estudo do sistema de garantia de direitos para a promoção da igualdade racial no Brasil. 2010. 320 f. Dissertação (Mestrado) - Curso de Direito, Universidade Federal de Santa Catarina, Florianópolis, 2010.

MARIZ, Renata. Barroso chama Joaquim Barbosa de 'negro de primeira linha' em discurso. O Globo. Brasil. 07 jun. 2017. Disponível em:

https://oglobo.globo.com/brasil/barroso-chama-joaquim-barbosa-de-negro-de-primeira-linhaem-discurso-21449394. Acesso em: 21 maio 2019.

Racismo Institucional - Teste de Imagem. Paraná: Governo do Paraná, 2016. P\&B.

Disponível em: https://www.youtube.com/watch?v=JtLaI_jcoDQ. Acesso em: 10 out. 2019.

PINHEIRO, José Maurício. Da iniciação científica ao TCC: uma abordagem para os cursos de tecnologia. Rio de Janeiro: Ciência Moderna, 2010. xv, 161 p.

SALES JUNIOR, Ronaldo. Democracia racial: o não-dito racista. Tempo Social, São Paulo, v. 18, n. 2, p.229-258, nov. 2006. Disponível em:

http://www.scielo.br/pdf/ts/v18n2/a12v18n2/. Acesso em: 21 maio 2019.

SANTOS, Isabel Aparecida dos. A responsabilidade da escola na eliminação do preconceito racial: alguns caminhos. In: CAVALLEIRO, Eliane. Racismo e Anti-racismo na educação: Repensando nossa escola. São Paulo: Summus, 2001. p. 97-115.

SANTOS, Sales Augusto dos. A Lei no 10.639/03 como fruto da luta anti-racista do Movimento Negro. In: SECAD, Secretaria de Educação Continuada, Alfabetização e Diversidade. Educação anti-racista: caminhos abertos pela Lei Federal 10.639/03. Brasília: Ministério da Educação, Secretaria de Educação Continuada, Alfabetização e Diversidade. 2005. p. 21-39.

SEPPIR, Secretaria Especial de Políticas de Promoção da Igualdade Racial da Presidência da República. Subsídios à II CONAPIR (Conferência Nacional de Promoção da Igualdade Racial). Brasília: Secretaria Especial de Políticas de Promoção da Igualdade Racial da Presidência da República - Seppir, 2009.

SOUZA, Arivaldo Santos de. Racismo Institucional: Para compreender o conceito. Revista da Associação Brasileira de Pesquisadores/as Negros/as (ABPN), [S.1.], v. 1, n. 3, p. 77 88, fev. 2011. ISSN 2177-2770.

SOUZA, Daiane. A Lei n ${ }^{\circ} \mathbf{1 0 . 6 3 9}$ na visão de Petronilha Beatriz Gonçalves e Silva. 2012. Disponível em: http://www.palmares.gov.br/?p=17211. Acesso em: 10 out. 2019.

THOMAZ, Omar Ribeiro; NASCIMENTO, Sebastião do. Entre a intenção e o gesto: a Conferência de Durban e a elaboração de uma pauta de demandas de políticas compensatórias

Saberes Pedagógicos, Criciúma, v. 4, n², maio/agosto 2020.- Curso de Pedagogia- UNESC 
no Brasil.Documento de Trabalho, São Paulo, v. 5, p.1-104, jun. 2003. Disponível em: http://nupps.usp.br/downloads/docs/dt0306.pdf. Acesso em: 10 out. 2019.

TRAPP, Rafael Petry. O antirracismo no Brasil e a Conferência de Durban: identidades transnacionais e a constituição da agenda política do Movimento Negro (1978-

2010). Cadernos do Ceom: Identidades, Chapecó, v. 24, p.1-18, dez. 2011. Semestral. Disponível em: https://bell.unochapeco.edu.br/revistas/index.php/rcc/article/view/1123. Acesso em: 10 out. 2019.

TREVISAN, Maria Carolina. O barulho e o silêncio por trás dos números sobre a cobertura jornalística da questão racial no Brasil. Revista Fórum. 2013. Disponível em: https://www.revistaforum.com.br/imprensa-e-racismo/. Acesso em: 21 maio 2019.

WIEVIORKA, Michel. O racismo, uma introdução. São Paulo: Perspectiva, 1946. 164 p. 